\title{
Tres cartas que nos recuerdan una de las mayores catástrofes humanas ocurrida en Santiago de Chile: Dos mil personas muertas el 8 de diciembre de 1863
}

\author{
Alfredo Palacios Roa' \\ Recibido: 8 de marzo de 2014 Aceptado: 28 de marzo de 2014
}

\begin{abstract}
Resumen
En este estudio se transcriben y analizan tres cartas que nos recuerdan una de las mayores tragedias humanas ocurrida en Chile, nos referimos al incendio que destruyó la iglesia de la Compañía de Jesús en 1863 que provocó la pérdida de la vida de dos mil concursos.
\end{abstract}

Palabras clave: Chile, Santiago, Jesuitas, Incendio, Religiosidad.

Three Letters that Remind us of One of the Greatest Human Catastrophes Occurred in Santiago, Chile: Two Thousand People Died on 8 December1863
Abstract
In this study are transcribed and analyzed three letters about one of the greatest human tragedies that occurred in Chile: the fire that destroyed the church of the Compañía de Jesús in 1863 which provoked the death of two thousand attendees.

Key words: Chile, Santiago, Jesuits, Fire, Religiosity.

Três cartas que nos lembram de uma das maiores catástrofes humanas ocorrida em Santiago de Chile: Duas mil pessoas mortas no dia 8 de dezembro de 1863

\begin{abstract}
Resumem
Neste estudo se transcrevem e analisam três cartas que nos lembram de uma das maiores tragédias humanas ocorridas no Chile, referimos-nos ao incêndio que destruiu a igreja da Companhia de Jesus no ano 1863 que provocou a vida de dos mil concursos.
\end{abstract}

Palavras chave: Chile, Santiago, Jesuítas, Incêndio, Religiosidade.

1 Chileno. Doctor en Historia. Profesor en la Universidad SEK, Chile.

E-mail: alfredo.palacios@uisek.cl 
Día martes en la tarde fiesta de nuestra Señora. Murieron dos mil personas devotas de nuestra Madre.

En un fuego lamentable se oyen gritos y lamentos porque las luces del templo al punto se corrompieron. Todos los fieles perdieron el año mil ochocientos

Incendio de la Compañía (Jijena, 1952: 81).

El 8 de diciembre de 2013 se cumplieron 150 años de uno de los eventos más tristes que recuerda la ciudad de Santiago de Chile: nos referimos al voraz incendio que en menos de "media hora" (Anónimo, 1864: 2) redujo a escombros el templo de la Compañía de Jesús y provocó la calcinación de cerca de dos mil fieles, en su gran mayoría mujeres, que ese día se daban cita en la casa de los ignacianos. Con todo, y a pesar del impacto mediático que en su momento causó la noticia, los habitantes de este conjunto urbano y las autoridades políticas y religiosas del país, poco o nada hicieron en recuerdo de dicha catástrofe y sus numerosas víctimas. ${ }^{2}$

Por ello, y en base a la búsqueda y posterior transcripción de tres desconocidas comunicaciones, en este artículo intentamos rescatar y valorar la memoria de esa trágica jornada y, con ello, esperamos contribuir a evocar y perpetuar el aniversario de una de las tardes más aciagas que los chilenos hayan presenciado en la época republicana, y uno de los acontecimientos más desgraciados que han afligido a todo el orbe. Quizás por esto último, un reconocido cronista del siglo XX señaló que:

"El incendio de la Compañía pertenece a los sucesos que se perpetúan en la memoria de los pueblos. Desde los países escandinavos hasta las regiones más meridionales de Italia, España y Portugal, la prensa, con rara uniformidad, dijo: El incendio de un templo en medio de una gran solemnidad religiosa y en el que las víctimas del fuego y la sofocación se cuentan por millares, es el primero que se registra en la historia de las naciones civilizadas" (Zañartu, 1975: 40).

Con todo, y a pesar de que la noticia rápidamente cruzó las fronteras y recorrió el mundo entero, y que el Estado chileno, en conjunto con algunos

2 Salvo en una pequeña esquela publicada en El Mercurio recordando los sucesos ocurridos en el país el día 8 de diciembre, en ningún otro periódico ni noticiario de Santiago se hizo alusión al famoso incendio. Véase: El Mercurio, Santiago, 9 de diciembre de 2013, A2. 
acaudalados vecinos, financiara dos monumentos en recuerdo del fatal acontecimiento (Palacios, 2011: 137-156), conforme pasaron los años este funesto suceso cayó en el más profundo olvido. Es más, luego de conmemorarse el primer aniversario de la catástrofe con una solemne misa en la Catedral Metropolitana "cada uno se entregó a sí mismo, echando en olvido la funesta lección" (Î́niguez, 1875: 148).

\section{El contexto de la tragedia}

En 1863, las festividades del Mes de María -celebrado en Chile entre el 8 de noviembre y el 8 de diciembre- atraían noche a noche a una inmensa concurrencia al templo de los jesuitas. ${ }^{3}$ Esta multitud, integrada en su gran mayoría por mujeres, iba en aumento en la medida que se acercaba la clausura de dicha festividad.

Ahora bien, por ser la última función de la popular celebración esta debía realizarse en la noche del 8 de diciembre; ciertamente, aquel acto de clausura se proyectaba con la mayor solemnidad y con una suntuosidad que no estaba al alcance de ningún otro templo en Chile. En consecuencia, y dado la magnificencia de aquel acto litúrgico, en la tarde de ese día una gran cantidad de mujeres se reunió en las inmediaciones del sagrado recinto esperando la apertura de las puertas. Algunos vecinos informaron que a eso de las tres de la tarde "aquello estaba lleno de mujeres en manto para quedar primeras en la entrada", y así ocupar un buen lugar cerca del altar mayor (Subercaseaux, 1908: 65). ${ }^{4}$ En efecto, cuando esto ocurrió, es decir cuando se dio la orden de abrir las puertas, el gentío se precipitó a tropel hasta atestar las espaciosas naves del templo, y aunque estuvieron llenas, conforme pasaron las horas siguieron acudiendo los fieles menos impacientes, haciéndose un lugar donde la aglomeración lo permitía.

De esta manera, a los pocos minutos el templo se repletó. Basta con señalar que en aquel lugar "donde con dificultad cabían tres mil personas" (Godoy, 1994: 306), bien pudieron ingresar según testigos unas "cinco mil"

3 El Mes de María, celebrado en el continente europeo en el mes de mayo, se conmemoró por primera vez en Chile en 1853 en el Seminario Conciliar por iniciativa de monseñor Joaquín Larraín Gandarillas, quien, al año siguiente, trasladó dicha festividad al mes de noviembre para que "se celebrara con flores frescas de primavera y su clausura coincidiera con la fiesta de la Inmaculada Concepción" (Serrano, 2004: 304).

4 Respecto al uso del manto en Chile, un viajero belga escribió a fines del siglo XIX lo siguiente: "en las mañanas todas las mujeres, de cualquier clase social a la que pertenezcan, no salen sino cubiertas de un manto negro que envuelve sus cabezas, dejando ver solo la cara, de tez mate y de ojos negros brillantes y profundos. Es la única toilette femenina que se admite en las iglesias" (Verniory, 1975: 40). 
(Casanova, 1871: 37). Importa decir que contribuyó a llenar el espacio, y a obstaculizar la posterior salida, las "crinolinas" y los tapetes de las damas, puesto que: "como entonces no habían asientos para las mujeres en ninguna iglesia, solo los hombres eran favorecidos con algunas sillas, nosotras teníamos que llevar una pequeña alfombra para sentarnos en ella, y no sufrir con el frío de los ladrillos" (Barros, 1942: 79). ${ }^{5}$

Así, cuando se verificó que era imposible que dentro de las paredes del templo cupiera una sola alma más, el capellán dio la orden de encender las más de "siete mil luces" que aquella noche, paradójicamente, llenarían de vida el recinto (El Ferrocarril, 9-XII-1863). La siguiente descripción ilustra detalladamente la fluorescencia que se alcanzó al interior del sagrado espacio:

"Un cordón de luz recorría toda la cornisa superior de la nave y formaba bajo su cúpula caprichosos emblemas. La iglesia se iluminaba con cera, estearina y parafina. La araña del medio del crucero tenía ochenta luces de estearina y dieciséis lámparas de parafina. En cada arco de la nave principal había una araña de ocho velas y cuatro lámparas. Al pie del tabernáculo se había colocado pocos días antes una media luna como de tres metros de largo, formada por el lado visible con vidrio pavonado y con lata por el reverso. Contenía vasitos de cristal con parafina en número de cincuenta, tapadas con lata. Esta media luna se colocaba un metro 20 centímetros distantes del tabernáculo y un metro 70 centímetros del altar en una mesa especial sobre la cual descansaba el poste redondo que servía de pie. Las luces de la cornisa de la iglesia eran de estearina. Cada vela era colocada en una plancha de lata y cubierta con un globo de cristal de color" (Vergara, 1906, II: 239).

Según se puede advertir en este último cuadro, eran elementos altamente inflamables los que permitían alumbrar la iglesia. En efecto, y aunque nunca se pudieron esclarecer las causas reales del fuego, según los contemporáneos cuando uno de los presbíteros allegó la mecha para encender la media luna que la imagen de la Virgen -representada como la Inmaculada Concepcióntenía en sus pies, uno de los quemadores expulsó una larga llamarada que inflamó unas cortinas que se hallaban a más de "cuatro pies de altura" (Esquerra, 1863: 8). ${ }^{6}$ Esa misma flama fue la que rápidamente se propagó

5 Las crinolinas eran vestidos confeccionados con un tejido hecho con urdimbre de crin de caballo y lino que permitía dar forma a una falda ahuecada en forma de campana, sujetada por varillas de metal o de "huesos de ballena que sustituían a los miriñaques o antiguos verdugados" (Sousa, 2007: 454).

6 El caso del "incendio de la Compañía de Jesús" fue llevado a la justicia para encontrar a los presuntos responsables, pero prontamente fue sobreseído por no encontrarse antecedente alguno que pudiera atribuir la culpabilidad a alguna persona. Sin embargo, en el 
por las cintas y guirnaldas, y en cosa de minutos entró en contacto con la bóveda de la iglesia la cual, por ser construida de madera y no de ladrillos "a causa de los temblores" (Godoy, 1994: 306) tan frecuentes en el suelo chileno, ardió con gran voracidad dando inicio al mortal incendio.

\section{Las cartas}

A continuación reproduciremos tres cartas que dan cuenta de los pormenores de aquella catástrofe humana. La primera, de autor anónimo y fecha desconocida, fue transcrita durante el primer semestre de 1864 por el escritor y periodista hispano León Carbonero en el tomo I de La Cruz. Revista religiosa de España y demás países católicos [etc.]. El motivo de reproducir esta misiva se basa en que en Chile es prácticamente desconocida, ya que, hasta el momento, no hemos tenido noticia del original, ni tampoco sabemos de la existencia de dicha revista en las colecciones de las principales bibliotecas del país.?

El segundo despacho, corresponde a un documento manuscrito conservado en los anaqueles del Archivo Nacional Histórico de Chile. Este documento, si bien tiene autor conocido y es el más breve de todos, su difícil grafía y manchas de humedad nos impiden transcribirlo en su totalidad. Sin embargo, y a pesar de estos inconvenientes, igual aporta datos de interés que permiten dimensionar la magnitud de la tragedia.

Finalmente, el tercer oficio que acá copiamos en forma íntegra fue redactado al día siguiente del incendio por el arzobispo de Santiago Rafael Valentín Valdivieso, quien por poco se cuenta entre las cientos de víctimas si no fuera porque algunos hombres lo atajaron antes de arrojarse a la hoguera buscando salvar personas. ${ }^{8}$

sumario levantado para averiguar las causas del siniestro, se dejó expresa constancia de la imprudencia con que se había aglomerado al interior del templo una gran cantidad de objetos inflamables, así como también "de la gran concurrencia que asistió a la celebración y sobrepasó la capacidad del sagrado recinto, sin haberse tomado ninguna medida de precaución" (Valdés, 1900: 42).

7 Para confirmar aquello, se pueden revisar los catálogos en línea de la Biblioteca Nacional de Chile, del Congreso Nacional, de la Universidad de Chile y de la Universidad Católica. Por otra parte, tenemos que agradecer a la Biblioteca Colombina de Sevilla el habernos digitalizado la misiva que acá reproducimos.

8 El capellán del arzobispo Valdivieso refirió que el prelado quiso lanzarse al interior del templo diciendo "es preciso salvar a los que se pueda", pero las personas que lo acompañaban impidieron ese acto de imprudente arrojo (Vergara, 1906, II: 244). 


\section{Criterios de transcripción}

Al copiar los documentos, y cuando así se ha requerido, hemos actualizado la ortografía, y en caso de la segunda carta, modificado la grafía. Por otra parte, toda interpolación en los tres originales, será explicada en una nota al pie de página.

\section{Carta anónima}

"El cuadro horroroso que presentaba el interior de la iglesia incendiada, a cuyo tétrico resplandor se veían masas compactas de seres vivientes, y en lontananza grupos de personas que por todas partes y en todas direcciones corrían clamando misericordia! El alarido inmenso de los que eran presas de las llamas, el montón y hacinamiento de unos sobre otros a un palmo de las puertas, que estaban clavados en el sitio; no son el fatal traje de la mujer, que tanto se presta a enredarse entre sí, y más aún con el miriñaque, sino que también el que los que venían detrás se agarraban con desesperación de los vestidos de los de adelante para poder trepar y pasar encima de ellas; así es que se veían varias murallas vivientes firmes y compactas como una sola roca, con los brazos extendidos pidiendo auxilio a la parte del público de afuera, que a pesar de los esfuerzos sobrehumanos que hizo, apenas se pudo salvar uno que otro por la atroz resistencia que encontraba, y además por el grave riesgo que corría, porque al llegarse cuarenta manos desesperadas lo agarraban, consiguiendo ser desprendidas de ellas por los esfuerzos de los compañeros de atrás, quedando todos muy mal parados y estropeados, con excepción de dos jóvenes que, lejos de poderse desprender, fueron subiendo y pasando por encima de los infelices, aumentando en número de víctimas.

¿Puede acaso formarse una idea la más remota de la desesperación que había en los seres amontonados y hacinados que tenían a un palmo la puerta, es decir, su salvación, y la del público que estaba enfrente impotente para salvarlo, y máxime en aquellos que mutuamente se reconocían siendo ya deudos, amigos o conocidos? Esta tragedia espantosa desde la declaración del incendio duró una media hora escasa, porque al marcar el reloj los treinta minutos, reinaba el más glacial y terrorífico silencio en toda la iglesia. No hay pincel que pueda pintar con vivos colores tan horrorosa escena; la pluma no resiste a describir un caso semejante y tan atroz que no se encuentra en los anales de la historia.

Al día siguiente conseguí por un coronel amigo mío, cuyo regimiento estaba de facción, penetrar en el interior del templo que solo 
conservaba sus paredes. No es posible describir el cuadro horroroso que se presentó a mi vista; el corazón se oprimía de tal manera que apenas se percibían sus latidos; estuve un momento, no quise recorrerlo todo; tuve bastante con el minuto que apenas permanecí, al entrar por la puerta principal y salir por una puerta lateral; a una distancia de 15 varas de la primera, y como 3 de la segunda, eran una masa informe de cadáveres que constaba 5 a 7 capas desde el suelo a la parte superior, de más de 5 varas de ancho por 10 o 12 de largo, presentándose la parte superior, de esqueletos carbonizados, arqueados en posturas de correr hacia la puerta. Por lo que toca a los grupos compactos, que había en cada puerta de salida, no quedaba vestigio alguno, porque los infelices fueron reducidos a cenizas; otros tantos cuadros horrorosos y repelentes dicen que prestaban en toda su extensión las naves laterales. Preguntándole a un oficial de policía qué cálculos se formaba de las víctimas que podría haber en el hacimiento por donde pasé al entrar por una puerta y salir por otra, me contestó que en el trecho que se había desocupado y que me enseñó, se habían contado 400 infelices: por desgracia conocí que quedaban todavía tres tantos más! ${ }^{9}$

Inútil es pensar que alma viviente pegó los ojos en tan aciaga noche; por todas partes, calles, plazas, veía usted correr madres en busca de sus hijos, y estos en busca de aquellas; maridos, en busca de sus esposas; en los semblantes no se veía pintado más que el horror y la desesperación. Para formarse una idea de la atroz desolación, ha habido jefe de familia (y distinguida) que perdió su esposa, cinco hijos y tres sobrinas; que la autoridad ha sellado siete casas por no haber quedado alma viviente, constando la familia de dos de ellas, de once y nueve personas. La pérdida horrorosa se califica de esta manera: 100 a 150 hombres, la cuarta parte de las víctimas señoras, ya de familias distinguidas, como acomodadas de la población, la otra cuarta parte de niños, y el resto de sirvientes mujeres; en una sola casa perdieron

9 Sobre la cifra oficial de personas fallecidas, tenemos que decir que tan difícil como la identificación de las víctimas resultó saber el número exacto de ellas. Los periódicos capitalinos comenzaron a publicar la nómina de muertos en base a la información que los deudos les entregaban a sus redactores. Así, cada día a partir del 10 de diciembre, salía un nuevo listado, se rectificaban errores y se entregaban datos de personas extraviadas. Con todo, a los 1719 cuerpos que según las nóminas oficiales fueron sacados del interior del templo, hay que sumar aquellos cadáveres que no pudieron formar parte de esa cifra por estar pulverizados o desmembrados, y los restos mortales de aquellas mujeres que fueron sacadas agonizando de esa hoguera y murieron en casas vecinas o a los pocos días producto de las graves quemaduras. Por lo tanto, no es exagerado decir, tal como se lee en la lápida que fue colocada en la fosa común que guarda los restos de aquellas víctimas: "incendio de la Compañía. ¡Dos mil víctimas más o menos!" (Riquelme, 1893: 153). 
nueve. La autoridad ha decretado la completa demolición del templo incendiado" 10 (Carbonero, 1864: 143-145).

\section{Carta de Pedro Félix Vicuña a su hija Luisa}

"Querida Luisa: por las varias partes y por los periódicos de mañana sabrás los pormenores de la catástrofe de anoche; felizmente ninguno de la familia ha perecido si no es Rosario Cañas. Ricardo Ovalle perdió [a] su mujer y cinco hijas. Doña Trinidad Larraín y la Eufrasia también perecieron ${ }^{11}$. Claudio salió esta semana a las 7 para el Melón y de allí a Puyaye [ilegible] Debemos dar gracias a Dios de que al sentimiento tan general no se añada el de ninguno de nuestra familia sino [borrón en el original] la Rosario Cañas. Ayer escribí a tu mamá, anoche y hoy también. Lo grande de la catástrofe ha univocado lo intenso del dolor quien allá esté sufriendo más por no saber lo que pasa [ilegible] Un abrazo a Gertrudis y [ilegible] p[adre]. Pedro Félix Vicuña". ${ }^{12}$

10 Obedeciendo a los "arranques de dolor" y a las primeras impresiones del momento, a los seis días del siniestro, un decreto supremo ordenó que se procediese a la demolición de las calcinadas murallas de la Compañía. Muchos de los que presionaron por la firma de ese documento, lo hicieron movidos por el rumor que decía que el clero pretendía reconstruir el templo para así honrar la memoria de las víctimas. Seguramente la pronta resolución del Ejecutivo, y que entendemos contó con el beneplácito del arzobispo para contener la delicada situación, sorprendió a todos aquellos que habían pregonado la idea de la demolición, ya que el mismo día de su publicación, lunes 14 de diciembre, los promotores de aquella medida habían convocado a la población para que se reunieran en el frontis del templo para iniciar una marcha hacia el palacio de gobierno con el fin de presionar al Presidente de la República para que ordenase de forma inmediata el derrumbe de los ennegrecidos muros. De esta manera, las cerca de dos mil personas que se dieron cita esa tarde se aprestaban a comenzar el desfile cuando un reconocido político leyó la siguiente ordenanza: "Art. $1^{\circ}$. Procédase a la demolición de las murallas del incendio del templo de la Compañía. Art. $2^{\circ}$. Concédase un término de diez días para la extracción de los cadáveres que están sepultados en dicho templo" (Vicuña Mackenna, 1864: 53).

11 Cumpliendo santamente sus deberes religiosos, doña Trinidad Larraín Gandarillas acudió aquella tarde acompañada por dos de sus hijos al templo y, junto con su hija Eufrasia de 21 años de edad, encontró la muerte aplastada por las campanas que se desprendieron de la torre (Larraín, 1982: 228).

12 Carta de Pedro Félix Vicuña a su hija Luisa, Santiago de Chile, 9 de diciembre de 1863. Archivo Histórico Nacional de Chile, Fondo Fernández Larraín, v. 166, p. 6. 
Figura 1: Gran incendio de la iglesia de la Compañía.

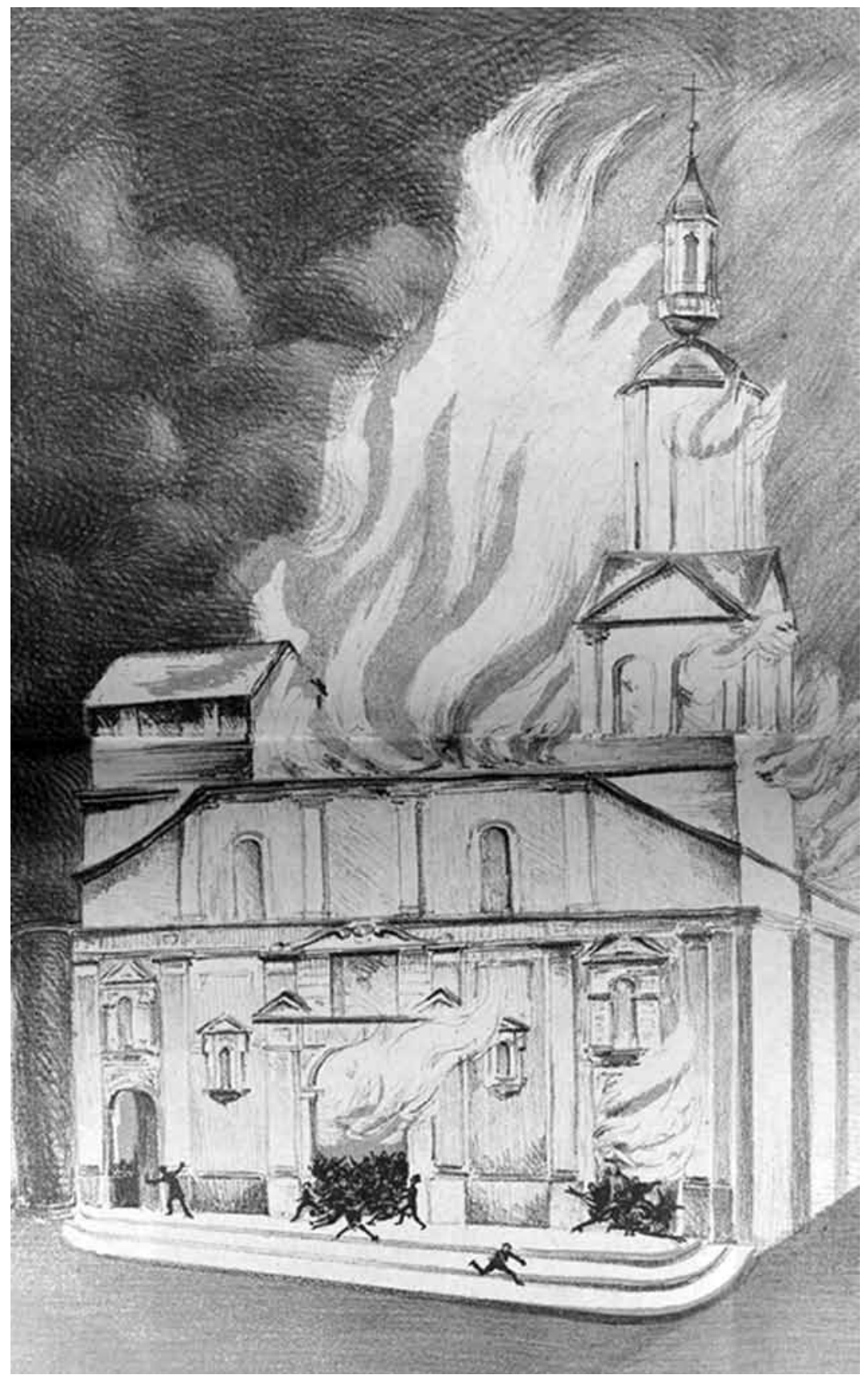

En La Lira Chilena, Valparaíso, 7 de diciembre de 1902. 


\section{Carta de Rafael Valentín Valdivieso}

"Mi venerable hermano y amigo:

La iglesia de la Compañía, ayer adornada con los más ricos atavíos que tal vez se han visto en Santiago, hoy no es más que ruinas, y lo que es mil veces peor, cubierta de cerros, materialmente hablando, de cadáveres calcinados los más y otros con sus vestidos intactos, sirviendo de base a esas moles carbonizadas. Iba ayer a las seis y tres cuartos de la tarde a principiarse el último día del Mes de María, los preparativos para encender la increíble multitud de luces se ejecutaban por muchos sacristanes, uno de los cuales tuerce una lámpara; ésta da fuego a las flores de mano que había cerca y casi instantáneamente se incendia el altar, el techo y la iglesia toda. Ésta se hallaba llena de gente y la misma multitud introdujo el desorden, luego se atascaron las salidas y ya no fue posible dar auxilio a los que venían detrás. Todas las puertas estaban abiertas, se hacían los mejores esfuerzos para salvar a las infelices que clamaban por auxilio; y todo era en vano, porque la masa de gente era tan compacta que más bien se conseguían sacar miembros a pedazos que aflojar aquel muro de cuerpos asfixiados. Casi no hay familia que por algún motivo no lleve luto, y en los semblantes de todos se pinta el pavor que ha causado este horrible acontecimiento. U[sted] vio las llamas y destrozos causados por el incendio de 1841; pero no se puede formar todavía la idea de lo que fue ayer, y como hay tantas víctimas humanas, éstas hacen olvidar la destrucción material. ${ }^{13}$

Los enemigos de la piedad solo olvidan la calamidad para hacer su negocio, piden que se estorbe la edificación del templo para convertirlo en jardín, teatro, plaza y qué sé yo qué otra cosa. Habrá, pues, que luchar con ellos y hacer fuerte a las asechanzas. Encomiende a Dios a doña Trinidad Larraín, a Eufrasia su hija y a doña Rosario Morán entre otras muchas de sus amigas. Hay quien hace pasar de mil muertos, casi todos mujeres, y tal vez una octava parte desconocida.

13 A las 9 de noche del 31 de mayo de 1841 se desató un incendio que redujo a cenizas cuanto material y objeto combustible había al interior del templo. Un periódico de la época refirió que las flamas enardecidas por los barnices de los altares se propagaron con una rapidez asombrosa a tal punto que, en menos de una hora, consumió: "la techumbre, la hermosa torre, recomendable por su estructura, y su precioso reloj, el tabernáculo, los altares de todas las distintas capillas, los ornamentos". En El Elector Chileno, Santiago, 2 de junio de 1841. Por su parte, el americanista Andrés Bello, que fue testigo de este siniestro, esbozó en prosa aquel terrorífico acontecimiento. Algunos de sus versos dicen así: "Entre la vasta ruina/ tal vez despierta y se encumbra/ llamarada repentina,/ que fantástica relumbra/ y todo el templo ilumina" (Bello, 1841: 6). 
Ruegue a Dios por todas y mande a su af[ectuosísi]mo y s[eguro] s[ervidor].

B[esa] s[u] m[ano]. Rafael Valentín, Arzobispo de Santiago". ${ }^{14}$

Imagen 2: Interior del templo al momento de declararse el incendio

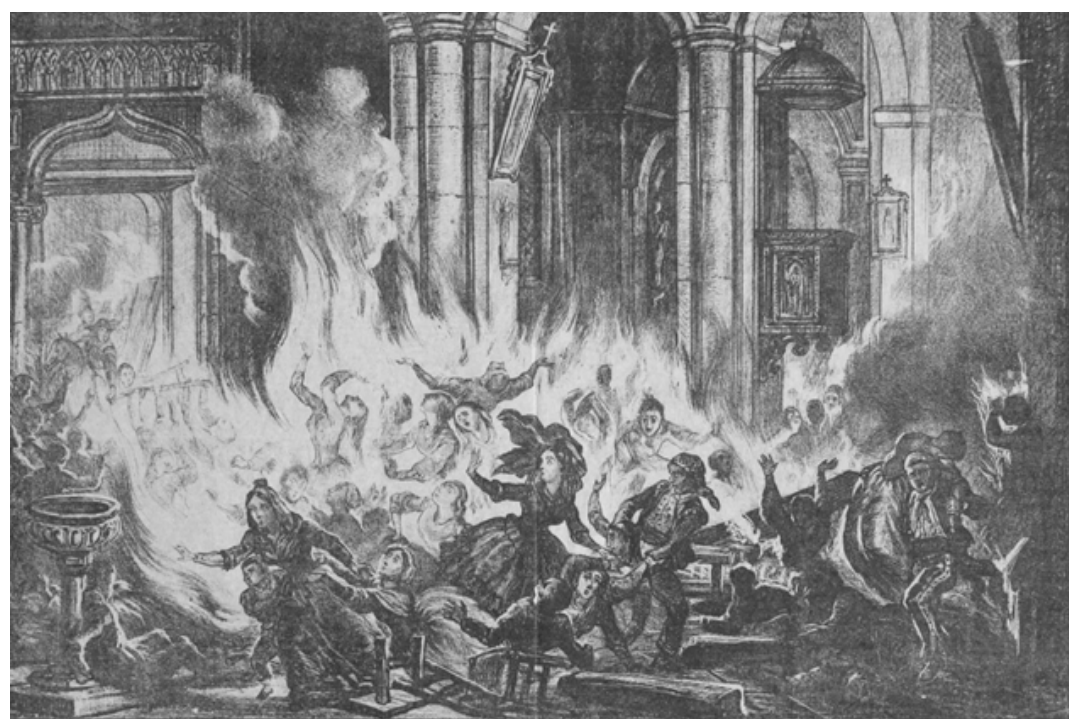

Fuente: Archivo Visual de Santiago.

\section{Colofón}

Ubicado en la intersección de las actuales calle Bandera y Compañía, a metros de la Plaza Mayor de Santiago (actual Plaza de Armas), el hoy desaparecido templo de los jesuitas desde sus primeros tiempos pareció estar dominado por una suerte de embrujo. Según la leyenda, el hechizo que rodeó a la casa de los hijos de San Ignacio comenzó a los pocos meses de haberse verificado el establecimiento de la orden en la capital del reino de Chile, hecho ocurrido el 12 de abril de 1593 (Hanisch, 1974: 8). Decimos esto porque, cuando se levantó la primera capilla que albergó a los religiosos, éstos depositaron en su interior la cabeza de una de las once mil vírgenes de

14 Carta del arzobispo de Santiago, Rafael Valentín Valdivieso, al obispo de Concepción, José Hipólito Salas, Santiago, 9 de noviembre de 1863. Archivo del Arzobispado de Santiago de Chile, Fondo de Gobierno, 149, carta 268. 
Colonia que traían en su tabernario (Ovalle, 1646: 338): "fatídica ofrenda -a decir de Benjamín Vicuña Mackenna- hecha al sitio del que debían volar al cielo de una vez tantas almas virginales" (Vicuña Mackenna, 1972, II: 21). Reproducimos la impresión de este reconocido historiador, ya que la colocación de aquella reliquia se realizó el día 21 de octubre, día de Santa Úrsula que rememora a la mártir sacrificada por los hunos junto a sus compañeras cristianas. ${ }^{15}$ Por lo tanto, a partir de esa fecha, todo comenzó a tener un símil dramático en el edificio de los jesuitas, especialmente luego de la ocurrencia de dos terremotos durante la época colonial -1647 y 1730- y un ataque incendiario durante la República -en 1841-.

Ahora bien, en relación al fatal incendio que estas tres cartas describen y que provocó la dramática muerte de cerca de dos mil fieles, tenemos que decir que inmediatamente después de que concluyó el prolongado enterramiento ${ }^{16}$, la población de Santiago de Chile comenzó a ser consolada con la idea de que sus familiares, amigos y conocidos habían fallecido, tal como lo demostró el médico encargado de determinar las causas específicas del masivo deceso, con "gran celeridad" (Tocornal, 1864: 558). ${ }^{17}$

En consecuencia, esta concepción de la calcinación fue la que comenzó a ser recurrida por los oradores capitalinos en las múltiples y solemnes exequias que se celebraron en las distintas parroquias y capillas del país. Una de ellas, y quizás la más importante de todas, por reunir a las máximas autoridades políticas y eclesiásticas de país, fue la que se desarrolló en la Catedral Metropolitana días después del fatal accidente. En aquella ocasión, en la que dominó el luto más riguroso, monseñor Mariano Casanova pronunció una elocuente y sentida oración, en la que exhortó a todos los concursos a templar el dolor de la abrupta partida con los consuelos de la fe. Algunas partes de su discurso fueron las siguientes:

15 Según la tradición medieval, una joven bretona llamada Úrsula se convirtió al cristianismo prometiendo guardar su virginidad. Al ser pretendida por un alto personaje de la nobleza de su reino, decidió realizar una peregrinación a Roma y así lograr la consagración de sus votos. A su regreso fue sorprendida por los hunos en la ciudad de Colonia donde ella, y las otras doncellas que la acompañaban, fueron martirizadas "por negarse a satisfacer los deseos sexuales de los bárbaros" (Ferreiro, 1991: 241).

16 A este respecto, tenemos que decir que la prensa de la época informó que recién el sábado 12 de diciembre, es decir, cuatro días después del incendio, pudieron concluir las faenas de sepultación. Fueron necesarias ciento sesenta y cuatro carretas -tanto de la policía urbana como del aseo público- para trasladar los cuerpos y doscientos hombres para cavar la enorme fosa de "veinticinco varas en cuadro" que contendría los restos mortales de las víctimas. El Ferrocarril, Santiago, 12 de diciembre de 1863.

17 Según este profesional, miembro de la Facultad de Medicina de la Universidad de Chile, "cuando las llamas se comunicaron a toda la iglesia y principió el incendio de los vestidos, cuyas quemaduras se consideran peores a las producidas por el agua caliente, o por el aceite hirviendo, los sufrimientos, gritos y lamentos se dejaban oír a bastante distancia. 
"Católicos! no pretendo yo agravar el peso de vuestro justo sentimiento, y menos intento pintaros los horrores de aquella noche cruel. Para vosotros, para mí vengo a buscar los consuelos de la religión, único consuelo verdadero [...] ¿En qué momento han perecido? Precisamente cuando los sentimientos de la piedad más tierna les llamaba a honrar su querida madre, la Virgen María [...] ¿Cómo se habían preparado para la muerte? [...] casi todas esas almas que hoy ya no existen en la tierra, se habían apresurado a confesar sus culpas con las más expresivas muestras de dolor [...] ¿En qué lugar murieron? Donde desearíamos todos dar nuestro último suspiro, en la casa del Señor, en el lugar sagrado, y en presencia del tabernáculo de su Dios" (Casanova, 1864: 1-14).

Con estas sentidas reflexiones, el pueblo de Chile y sus máximas autoridades rindieron el último adiós a las víctimas del incendio, con el firme compromiso -siguiendo la intención formulada por monseñor Casanova en su plegaria- de no olvidar jamás el recuerdo de ese día y legar a las generaciones venideras "nuestro amor hacia vosotras"(Casanova, 1864: 14). Por lo tanto, y entendiendo que conforme pasaron los años este triste recuerdo se fue desvaneciendo de la memoria histórica de los habitantes de Santiago de Chile, a través del rescate y publicación de estas tres sentidas cartas quisimos volver a evocar ese duro momento que enlutó a este lejano país y, quizás con ello, motivar nuevas investigaciones en torno a esta espantosa catástrofe.

\section{Referencias bibliográficas}

\section{Fuentes primarias}

\section{a.- Documentales}

Archivo del Arzobispado de Santiago de Chile, Fondo de Gobierno, 149, carta 268.

Archivo Histórico Nacional de Chile, Fondo Fernández Larraín, v. 166, p. 6.

\section{b.- Periódicos}

El Elector Chileno, Santiago, 2 de junio de 1841.

El Ferrocarril, Santiago, 9 y 12 de diciembre de 1863.

La Lira Chilena, Valparaíso, 7 de diciembre de 1902.

El Mercurio, Santiago, 9 de diciembre de 2013, p. A2. 


\section{Fuentes Secundarias}

ANÓNIMO (1864). Horrible incendio y gran catástrofe acaecida el día 8 de diciembre de 1863 en Santiago de Chile. Barcelona: Imprenta de Juan Llorens.

BARROS, M. (1942). Recuerdos de mi vida. Santiago de Chile: Editorial Orbe.

BELLO, A. (1841). El incendio de la Compañía: canto elegíaco. Santiago de Chile: Imprenta y litografía del Estado.

CARBONERO, L. (1864). Espantosa catástrofe. La Cruz, revista religiosa de España y demás países católicos, t. I, pp. 143-145.

CASANOVA, M. (1864). Oración fúnebre que pronunció el presbitero Dr. D. Mariano Casanova en las exequias celebradas el 6 de diciembre de 1864, en la iglesia Metropolitana por las víctimas del incendio de la Compañía el 8 de diciembre de 1863. Santiago de Chile: Imprenta del Correo.

CASANOVA, M. (1864). Oración fúnebre que pronunció el presbitero Dr. D. Mariano Casanova en las exequias celebradas el 16 de diciembre de 1864 en la Santa Iglesia Metropolitana, por las víctimas del incendio de la Compañía. Santiago de Chile: Imprenta del Ferrocarril.

CASANOVA, M. (1871). Historia del templo de Compañía de Santiago de Chile y de su incendio acaecido el 8 de diciembre de 1863. Valparaíso: Imprenta del Mercurio.

EZQUERRA, N. (1863). Resumen histórico del gran incendio de la Compañía acaecido en la noche del día 8 de diciembre de 1863. Valparaíso: Imprenta de Antonio Monticelli.

FERREIRO, J. (1991). La leyenda de las once mil vírgenes. Sus reliquias, culto e iconografía. Murcia: Secretariado de Publicaciones de la Universidad de Murcia.

GODOY, H. (1994). Ignacio Domeyko, un testigo de su tiempo: memorias y correspondencia. Santiago de Chile: Imprenta Universitaria.

HANISCH, W. (1974). Historia de la Compañía de Jesús en Chile: (1593-1955). Santiago de Chile: Editorial Francisco de Aguirre.

í̃IGUEZ, A. (1875). Páginas literarias. Miscelánea de composiciones: 1864-1874. Valparaíso: Imprenta Colón.

JIJENA, L. (1952). Poesía popular y tradicional americana. Buenos Aires: Editorial Espasa-Calpe.

LARRAín, C. (1982). La familia Larraín: sus orígenes en España e historial de la rama mayor de Chile. Santiago de Chile: Academia Chilena de Historia.

OVALLE, A. (1646). Histórica relación del reino de Chile. Roma: Francisco Cavallo. 
PALACIOS, A. (2011). "¿Piedad o fanatismo? La historia de los monumentos a las víctimas del incendio de la Compañía de Jesús", en Anuario de la Historia de la Iglesia en Chile, № 29, p. 137-156.

RIQUELME, D. (1983). El incendio de la iglesia de la Compañía. Santiago de Chile: Imprenta Cervantes.

SERRANO, Sol. "El poder de la obediencia: religiosas modernas en la sociedad chilena del siglo XIX, en: GONZALBO, P. (2004). Las mujeres en la construcción de las sociedades iberoamericana. Sevilla: Escuela Superior de Investigaciones Científicas (CSIC), p. 295-313.

SOUSA, F. (2007). Introducción a la historia de la indumentaria en España. Madrid: Ediciones Istmo.

SUBERCASEAUX, R. (1908). Memorias de cincuenta años. Santiago de Chile: Imprenta y litografía Barcelona.

TOCORNAL, F. (1864). "Relación médica de lo sucedido en el templo de la Compañía el 8 de diciembre de 1863", en Anales de la Universidad de Chile, № 25, p. 556-559.

VALDÉS, I. (1900). El Cuerpo de Bomberos de Santiago: 1863-1900. Noticias para su historia y datos sobre otros Cuerpos de Bomberos de Chile. Valparaíso: Imprenta Sud-Americana.

VERGARA, R. (1906). Vida y obras del ilustrísimo y reverendísimo señor doctor don Rafael Valentín Valdivieso. Santiago de Chile: Imprenta Nacional, t. II.

VERNIORY, G. (1975). Diez años en Araucanía, 1889-1899. Santiago de Chile: Ediciones de la Universidad de Chile.

VICUÑA MACKENNA, B. (1864). Relación del incendio de la Compañía acaecido el 8 de diciembre de 1863. Santiago de Chile: Imprenta del Ferrocarril.

VICUÑA MACKENNA, B. (1872). Miscelánea. Santiago de Chile: Imprenta de la librería de El Mercurio, t. II.

ZAÑARTU, S. (1975). Santiago: calles viejas. Santiago de Chile: Editorial Gabriela Mistral. 